\title{
VERSIONES ESPAÑOLAS DE LAS OBRAS TEATRALES DE ALEXANDRE DUMAS (HIJO). II
}

Rosa Calvft

$U N E D$

Ninguna de las obras teatrales de Alexandre Dumas (hijo) dio lugar a tantas versiones al castellano como La Dame aux camélias, de la que nos ocupamos en la primera parte de nuestro trabajo'. Relacionaremos, a continuación, las versiones españolas del resto de la producción del autor, manteniendo el mismo esquema de presentación que habíamos propuesto en la citada primera parte.

Dado el número de las versiones, para no alargarnos demasiado, dentro de la comparación de la estructura dramática de las obras, nos limitaremos a reseñar lo más destacado, evitando una pormenorización demasiado minuciosa. Seguiremos el orden cronológico de los estrenos de las obras en París.

Le Demi-monde (Gymnase Dramatique, 20 de marzo de 1855).

Le Demi-monde, término inventado por Dumas hijo, que pasó pronto al vocabulario usual, es una de las mejores obras del autor. Describe con crudeza un segmento social que amenaza la estabilidad de las familias honradas, y que se mueve, según él, como una isla flotante en el océano parisiense:

1 Publicado en el número anterior de esta Revista. Cf.: R. CALvet, "Versiones españolas de las obras teatrales de Alexandre Dumas (hijo): I La dame aux camélias", Epos, n. ${ }^{\circ}$ V, Madrid, UNED, 1990. 
...«qui appelle, qui recueille, qui admet tout ce qui tombe, tout ce qui émigre, tout ce qui se sauve de la terre ferme, sans compter tous les naufragés de reencontre, et qui viennent on ne sait d'où».

\section{(Le Demi-monde, acto II. escena 9)}

Este grupo social, del que forman parte las numerosas «damas de las camelias» del momento, es bien conocido por el autor. Su padre lo introduce en él desde bien joven. Pero el joven Dumas es bien distinto de su progenitor y reaccionará dedicando gran parte de su producción y de su vida a combatir la perniciosa influencia de este tipo de personas.

La pieza presenta las argucias de una mujer de ese mundo, la falsa baronesa d'Ange, para alcanzar la consideración de la sociedad, por medio de un honorable matrimonio.

El crecido número de versiones españolas de la obra, testimonian la difusión que la pintura social de Dumas (hijo) alcanzó en nuestro país.

\section{VERSIONES ESPAÑOLAS}

Primera versión: $S U S A N A^{2}$

Autor: José M." García.

Estreno: Teatro del Circo de Madrid en 1857.

\section{Aspectos formales}

1. Título: se ha modificado, aludiendo al nombre de la principal protagonista.

2. Número y nombre de los personajes: se mantiene el número y el nombre, traduciendo los nombres de pila y manteniendo los apellidos.

3. Acción: se mantiene en París y en la época.

2 J. M." Garcia, Susana, Madrid, Imprenta C. González, 1857. 
4. Número de actos: se respetan los cinco del original.

5. Se mantiene la prosa.

6. Acotaciones escénicas: se traducen literalmente.

\section{Estructura dramática:}

En esta versión se reducen considerablemente los detalles ofrecidos en la obra original, y los largos parlamentos entre los actores se transforman en diálogos rápidos.

Se suprime la escena 8 del acto II, la 13 del acto III y las escenas $4,5,10$ y 11 del acto IV, mientras que se añaden dos más al acto $\mathrm{V}$, a base de desdoblar las del original.

\section{Contenido temático}

Las modificaciones de la versión afectan al contenido de las intrigas secundarias. Una de ellas es la que tiene como eje a Valentine de Santis, que ha abandonado el hogar conyugal y pretende volver con su esposo tras dilapidar su patrimonio. En la obra francesa, se detallan los pormenores de la vida de esta esposa infiel, que termina fugándose con un corredor de bolsa que huye de la justicia después de apropiarse del dinero de sus clientes. En la versión, este último detalle se omite y no se concede la misma importancia al personaje, reduciendo considerablemente sus intervenciones.

Se reduce también la importancia del personaje de Mme. de Lornan, enamorada de Olivier y por cuya defensa se produce un duelo, aunque éste se mantiene, como desencadenante del conflicto final.

No se producen grandes modificaciones respecto al tema central de la obra. La presentación del mundo que rodea a Suzanne d'Ange es bastante exacta, aunque la descripción del llamado «demi-monde» (acto II, esc. 9) es menos pormenorizada, restándole así crudeza. Se evitan también los largos parlamentos de Olivier de Jalin sobre la amistad, las mujeres, etc. Se añaden unas frases finales en boca de este personaje, que chocan con la personalidad que le había conferido el autor, $y$ en las que da gracias al cielo por el amor que ha encontrado en Marcela. Para el Olivier de Dumas, el cielo no parece ser cuestión en ningún caso.

\section{Calidad literaria}

El «exceso» del verbo dumasiano, sus famosos mots, su esprit, no tienen fácil traducción. Esta versión se limita a traducir la idea general de la co- 
media, con las modificaciones señaladas, en un castellano no siempre afortunado.

Segunda versión: NO ES ORO TODO LO QUE RELUCE

Autor: Sin nombre del traductor.

Sin noticias del estreno.

I. Aspectos formales

1. Título: Se ha modificado.

2. Personajes: se mantiene el número, transformando los nombres en españoles: Olivier de Jalin es Justo Mendoza; R. de Nanjac, César de Guzmán; el marqués de Thonnerins, duque de Cumbres Mayores; H. Richmond, Marcos Morales; Suzanne d'Ange, Magdalena, condesa de Montevano; Valentine de Santis, Leonor, vda. de Garcipérez; la vicomtesse de Vernières, vizcondesa del Egido; Marcelle, Cándida; Latour, Urdaneta.

3. Acción: se traslada a España y al mundo madrileño de la época.

4. Número de actos: se mantienen los cinco del original.

5. En prosa.

6. Acotaciones escénicas: $\sin$ interés.

7. Estructura dramática:

Mantiene el esquema de la obra original, salvo la supresión de una escena, la 13, del acto tercero y el aumento de otra escena en el acto cuarto.

${ }^{3}$ ANónimo, No es oro todo lo que reluce, Madrid, Imprenta de José Rodriguez, 1857. 


\title{
II. Contenido temático
}

Se ha mantenido el contenido de la obra de Dumas (hijo), que se traduce integramente. El interés de la versión reside en el intento de transponer el universo creado por el autor al mundo madrileño; así Mme. de Santis que "aime le spectacle» se convierte en "abonada al Real»; los coches se alquilan en "casa de Lázaro»; «une propriété en Touraine» pasa a ser "un olivar de Córdoba», «la campagne» es Aranjuez o Carabanchel, etc. Algunos diálogos sitúan la época:

\author{
VALENTINE \\ "Combien payez-vous ici?». \\ Olivier \\ «Trois mille francs» (doce mil reales). \\ VALENTINE \\ "Mais vous êtes dans les nouveaux quartiers, dans un désert". \\ "Pero esta calle de Barquillo está muy retirada». \\ ...«Moi, j’ai trouvé, rue de la Paix un amour d'appartement.» \\ ...en la calle de Atocha»...
}

(Acto I, escena 1)

Otros, sin embargo, valga la ironía, parecen más actuales:

\begin{abstract}
SuZANNE
«Mais, quand on habite à la campagne, on ne peut pas toujours répondre de son exactitude».

«Pero el ferrocarril de Aranjuez está como Dios quiere, las locomotoras tienen poca fuerza, las paradas se prolongan, en fin, yo contaba llegar dos horas antes").
\end{abstract}

En algunas ocasiones, el traductor añade de su cosecha parlamentos condenatorios sobre los males presentados en escena, que no son pocos, como tampoco lo son las largas disertaciones de Olivier de Jalin, el protagonista condenando esto y aquello. Así por ejemplo, donde Dumas dice:

«Aller cherchez un homme, lui serrer la main, l'appeler son ami et lui prendre sa femme, tant pis pour ceux qui ne pensent pas comme moi, mais je trouve cela honteux, répugnant, écoeurant".

"Yo no podría entrar en una casa, estrechar al dueño la mano de amigo 
y buscarle después las vueltas para robarle su tesoro. Semejante conducta siempre me ha parecido vergonzosa y degradante, como lo es siempre la deslealtad».

A esto se añade:

Morales

"Pues es moneda corriente, medio usado hasta la saciedad y preconizado en las novelas y hasta en el teatro; sin considerar que no hay situación más degradante que la de un cortejo en presencia del marido». MENDOZA

"La mujer misma pierde en la estimación de su amante, porque en vez de ver en ella aquella criatura angelical, ornada de los encantos de lo desconocido y con la admiración y el respeto que siempre inspira, aún al más depravado, la austeridad del deber, no ve más que una mujer sensual y liviana, privada de la estimación de las otras mujeres puras, y luchando siempre entre el temor y el remordimiento. Pronto ve trocado el adúltero aquel hermoso cuadro de Murillo con marco de oro por una mala litografia del realizado ensueño que forjó su imaginación calenturienta».

(Acto I, escena 3)

En la descripción de las integrantes del «demi-monde», encontramos las siguientes referencias:

"Las mujeres adúlteras y las jóvenes deshonradas, se escondían antes en las Arrepentidas, si eran pobres, en las antiguas monjas de Pinto o en las Salesas, si eran de alta clase»

(Acto II, escena 9)

\section{Calidad literaria}

$\mathrm{Al}$ intentar, sin éxito, imitar el estilo del autor francés, tan característico, el traductor español emplea un lenguaje ampuloso y artificial, que no se acerca en absoluto al del modelo.

Tercera versión: $D E M I-M O N D E$

Autor: Luis Valdés ${ }^{4}$.

Estreno: Teatro de la Comedia de Madrid, 31 de octubre de 1883.

4. Laldé, Demi-monde, Madrid, Imprenta de Cosme Rodríguez, 1883. 


\section{Aspectos formales}

1. Titulo: se mantiene, suprimiendo el artículo.

2. Número y nombre de los personajes: se mantiene el número traduciendo los nombres y manteniendo los apellidos.

3. Acción: $\sin$ especificar; se supone que mantiene la del original.

4. Se mantienen los cinco actos del original.

5. En prosa.

6. Acotaciones escénicas: se traducen las del original.

7. Carece de interés aludir a la estructura dramática.

\section{Contenido temático}

La versión de Valdés toma de la obra de Dumas (hijo) la mayor parte de los diálogos, que se limita a traducir literalmente, pero omite los detalles que no le parecen convenientes, recortando aquí y allá. Así por ejemplo: la relación de Olivier con Mme de Lornan, que pasa de ser una mujer que está dispuesta a embarcarse en una aventura a:

OLIVIER

"Y ya no pensaba más en la condesa y no por estar seguro, como lo estoy, de que no alcanzaré jamás ninguna esperanza, pues es muy virtuosa...»

(Demi-monde, versión Valdés, acto I, esc. 3)

Se omite también la descripción pormenorizada de las infidelidades de Valentine (acto I, esc. 3).

La descripción del "demi-monde», que constituye el eje de la obra, se salda con tres o cuatro frases en esta versión, aludiendo al sentido general de la pintura del autor francés.

Sin embargo, cuando Marcela (Marcelle) pide consejo a Olivier sobre el modo de organizar su futuro, alejándose de las malas influencias de la 
sociedad que le hace frecuentar su tía, el autor español añade ideas y pormenores que no están en el original (acto II, esc. 10).

Del último acto, se suprime la huida de Valentine con Latour, el corredor de bolsa.

La versión de Valdés "suaviza», pues, el original, conservando el sentido de la intriga principal, pero evitando presentar en escena detalles de las intrigas secundarias que aumenten el tono escabroso de la obra. Por eso presenta las argucias de la cortesana para casarse, pero evita presentar las de mujeres casadas en busca de amantes.

\section{Calidad literaria}

El estilo de Valdés, del que ya conocemos otras versiones es siempre ramplón y de escasísima calidad literaria.

Cuarta versión: $M A P A-M U N D I$

Autor: Francisco Flores García ${ }^{5}$

Estreno: Teatro Eslava de Madrid el 3 de diciembre de 1883.

\section{Aspectos formales}

1. Título: se ha modificado, parodiando el del original.

2. Número y nombre de los personajes: se suprimen varios de ellos, cambiando el nombre al resto. Suzanne pasa a ser Catana; Marcelle, Micaela; la vizcondesa, Doña Paz; Olivier, Oliver; Raymond, Facundo; Hyppolite, Polito; el marqués, Sr. de Cordelejo.

3. Acción: se traslada al Madrid de la época.

4. Número de actos: se reducen a un acto, en cuatro cuadros.

'Flores García, Mapa-mundi, Madrid, Establecimiento Tipográfico de M.P. Montoya y Cía, 1883. 
5. En verso.

6. Acotaciones escénicas: se detallan los decorados que deben cambiarse a la vista del público para cada cuadro.

\title{
7. Estructura dramática:
}

Al tratarse de una obra en un acto, la estructura dramática no puede compararse con la del original, al que evidentemente no sigue.

\section{Contenido temático}

Se trata de una obra completamente distinta del original, un juguete cómico en el que se toman una serie de motivos dramáticos que constituyen el argumento, combinándolos de forma disparatada. El ambiente sigue siendo el de un mundo de vida y costumbres licenciosas, en el que se guardan poco las formas:

«Eva manzana y con ello pecado,*

Usted se halla rodeado,

y pongo á Dios por testigo,

de mujeres que en su afán

de lujo y ostentación

mantienen la tradición

de la señora de Adán»

(Mapa-mundi, cuadro $\left.2 .^{\circ}\right)$

\section{Calidad literaria}

El tono de chanza y de comicidad del peor gusto se acomoda a un lenguaje vulgar, del que presentamos una pequeña muestra:

\author{
OLIVER \\ "Yo tamaba con locura \\ y al saber que te casabas...
}

* (así en el texto) 
CATALANA

«De veras? ¡Con que mamabas!»

OLIVER

«Si, como una criatura»

(Mapa-mundi, cuadro $\left.4 .^{\circ}\right)$

El interés de la pieza reside únicamente en ser una prueba de la difusión de la obra de Dumas en nuestro país, proyectándose en todos los géneros.

Quinta versión: $D E M I-M O N D E$

Autor: F. Pérez Capo ${ }^{6}$.

Sin noticias de estreno

I. Aspectos formales

1. Titulo: se ha mantenido, suprimiendo el artículo.

2. Número y nombre de los personajes: se mantiene el número y se traducen al castellano los nombres, suprimiendo los apellidos.

3. Acción: se mantiene en París

4. Número de actos: se mantienen los cinco del original

5. En prosa.

6. Acotaciones escénicas: se traducen literalmente las del original.

7. Estructura dramática:

Se mantiene exacta la estructura dramática original, salvo la supresión del corte entre la escena $1 .^{\mathrm{a}}$ y la $2 .^{\mathrm{a}}$ del francés, que en la versión constituyen una sola, quedando el acto I con 12 escenas, en vez de las trece del original.

- F. Pérez Capo, Demi-monde, Barcelona, Casa ed. Maucci, sin año de edición, pero por las referencias, posterior a 1910 . 


\section{Contenido temático y calidad literaria}

Se trata de una traducción literal, palabra a palabra, diccionario en mano, de la obra francesa, lo que da lugar a una considerable merma en la calidad literaria de la versión respecto del original.

Sexta versión: $D E M I-M O N D E$

Autor: Rafael Cansinos Assens ${ }^{7}$

Sin noticias del estreno

I. Aspectos formales

1. Título: se ha mantenido

2. Número y nombre de los personajes: se mantienen ambos.

3. Acción: se mantiene en Paris.

4. Número de actos: se reducen a cuatro.

5. En prosa.

6. Acotaciones escénicas: se traducen.

7. Estructura dramática:

Se suprime parte de la escena 4, así como la 5 , la 6 y la 7 completas del primer acto, $y$ las dos primeras del segundo acto, estando constituido el primer acto de esta versión por el resto de las escenas de los dos primeros actos del francés. A partir del tercer acto del francés, que se convierte en el segundo de la versión, ésta traduce fielmente el texto original.

7 R. Cansinos Assens, Demi-monde, Madrid, Tipografia Cervantes, 1919. 


\section{Contenido temático y calidad literaria}

Se suprimen anécdotas, como las relativas al episodio de Valentine, a la escasa fortuna de la vizcondesa y a otros detalles de menor importancia. En cuanto al resto, traduce el texto original en un castellano discreto.

Le fils naturel (Gymnase Dramatique, 16 de enero de 1858)

El título indica ya el tema de esta obra. Se traduce con gran celeridad en nuestro país y da lugar a dos versiones. Cada uno de los traductores pretende tener la expresa autorización del autor de la obra para acometer en exclusiva la traducción, lo que provoca un contencioso en el juzgado.

\section{VERSIONES}

Primera versión: UN HIJO NATURAL

Autor: José de Olona'.

No se estrenó.

\section{Aspectos formales}

1. Título: se mantiene, cambiando el artículo.

2. Número y nombre de los personajes: se mantiene el número, alterando los nombres: Clara Vignot pasa a ser Clara Derval; Henriette Sternay, Enriqueta Dovigny; Hermine, Herminia; la marquise, la marquesa, Mme Gervais, Margarita; Charles Sternay, Carlos Dovigny; Jacques, Eduardo; le marquis d'Orgebac, el marqués de Monroso; Aristide Fressard, Jacinto Fressard; Lucien, Luciano; le docteur, Blanchard.

- El juzgado de Lavapiés declara: no haber lugar al interdicto de retener deducido por

D. Luis de Olona contra la traducción y representación de la comedia.

$\checkmark$ J. DE OLONA, Un hijo natural, Madrid, Imprenta de J. Rodríguez, 1858. 
3. Acción: se mantiene en París, conservando la fecha de 1819 para el prólogo ${ }^{10}$.

4. Se mantienen los cuatro actos y el prólogo.

5. En prosa.

6. Acotaciones escénicas: se traducen literalmente.

\section{Estructura dramática:}

El primer acto suprime dos escenas, al reunir en una sola, por un lado, la 2 y la 3 y, por otro, la 9 y la 10 del original. El resto de la obra mantiene la misma estructura del texto francés, alterando algunos detalles y traduciendo de forma literal el resto.

\section{Contenido temático}

Las principales alteraciones en cuanto a éste son las siguientes: Henriette, esposa del padre de Jacques (el hijo no reconocido), pide a éste que recoja en casa de $\mathbf{M}$. de Nervaux unas cartas de amor que la comprometen. En la versión española, las cartas comprometen al marido de la dama. $M$. de Nervaux, una de las primeras figuras políticas del pais, está al frente de la oposición, y los documentos demuestran la conspiración política en la que tanto M. de Nervaux como el marido de Henriette se hallan inmersos. Se convierte, pues, a Henriette en una abnegada esposa, en lugar de infiel.

Otro detalle significativo, que no se da en el original: Aristide (Jacinto) Fressard, el notario y padrino de Jacques (Eduardo), tiene una numerosa prole (12 hijos). El feliz padre comenta al marqués que si fuera prusiano habría obtenido una medalla, pues en Prusia, el rey condecora a los padres en esa situación. Decimos que es un detalle significativo, pues no existiendo en el original (en la obra francesa Aristide tiene nueve hijos), se repite en otra de las versiones, a la que aludiremos en tercer lugar.

Esta versión altera también ligeramente el desenlace. En la obra francesa el padre, que no había querido reconocer a su hijo, quiere hacerlo cuando éste se ha convertido en un personaje relevante para la vida política de su país, y va a recibir un título nobiliario por los servicios prestados a la patria. Jacques, el hijo, rehúsa ser reconocido, pero consigue que su padre sea nom-

10 La obra de Dumas hijo consta de cuatro actos y un prólogo. En éste se dan a conocer las circunstancias del nacimiento del protagonista, que es entonces un niño de corta edad. En el primer acto lo encontramos convertido en un joven de casi veinticinco años. 
brado conde en su lugar, como forma noble de vengarse de los desprecios infringidos. El padre acepta encantado ese final.

En la versión española, ante las mismas circunstancias, la reacción del padre varia:

DOVIGNY

«No, ya que no puedo obtener el título de padre, no quiero el de conde. Empiezo a comprender que soy indigno de ambos, pero espero que no me negaréis el de vuestro mejor amigo»

(Un hijo natural, versión Olona, acto IV, esc. 9)

Evidentemente, esta reacción altera el contenido de la obra, que resulta más moralizador que en el texto original, rehabilitando en parte la denostada figura del padre.

\section{Calidad literaria}

La traducción es muy literal, resultando un texto de un muy pobre castellano.

Segunda versión: EL HIJO NATURAL ${ }^{11}$

Autores: Luis Cortés y Suaña, José M." Escudero y Manuel Padilla.

Estreno: Teatro de Novedades de Madrid, 13 de marzo de 1858.

\section{Aspectos formales}

1. Titulo: se ha traducido.

2. Número y nombre de los personajes: se mantiene el número. Se traducen los nombres y se conservan los apellidos. zález, 1858. 
3. Acción: se mantiene en Francia, en los mismos lugares y fechas.

4. Número de actos: los mismos cuatro actos y prólogo del francés.

5. En prosa.

6. Acotaciones escénicas: se detallan extraordinariamente, tanto los decorados como las reacciones de los personajes.

7. Estructura dramática de las obras:

Como en la versión anterior, se unen las escenas 2 y 3 del acto I en una sola. Se ha suprimido el episodio de las cartas de Henriette, al que hemos hecho referencia. Así mismo se suprime la escena 9 del mismo acto. En el tercero, se suprime la primera escena.

El resto de la obra se reduce a base de glosar las ideas de cada parlamento, resumiendolas.

\section{Contenido temático}

Existe también al final una mayor lección moral, añadiendo un parlamento de invocación a Dios por parte de Clara, la madre abandonada. Salvo estas excepciones, no se altera el contenido de la obra francesa, aunque se aligera de las largas disertaciones frecuentes en el autor francés.

\section{Calidad literaria}

Escasa en su conjunto, con un castellano que deja bastante que desear.

Tercera versión: $E L$ HIJO NATURAL $L^{12}$

Autora: Emilia Serrano de Wilson.

Sin noticias del estreno. 1861.

E. SerRano de WiLSON, El hijo natural, Valparaiso, Imprenta y Libreria del Mercurio, 


\section{Aspectos formales}

1. Título: se ha mantenido.

2. Número y nombre de los personajes: se mantiene, traduciendo los nombres de pila.

3. Acción: se mantiene el tiempo y los lugares de la acción.

4. Se mantiene el número de actos.

5. En prosa.

6. Acotaciones escénicas: se suprimen.

7. Estructura dramática:

Se trata de una traducción literal y ramplona de la obra francesa, que dudamos si la autora conocía o se limitó a manejar la versión de Olona, a la que sigue sospechosamente, hasta en el detalle anteriormente aludido, de la medalla prusiana a la paternidad.

Un père prodigue (Gymnase Dramatique, 30 de noviembre de 1859)

Esta obra, junto con la anterior, tiene un carácter autobiográfico. El padre pródigo tiene los rasgos de gallardía y generosidad, pero también de inconsciencia, de frivolidad y de pasión por los placeres menos espirituales que, según parece, eran propios de Dumas padre.

Sólo conocemos una versión castellana

\section{Versión: EL PADRE PRÓDIGO}

Autores: Cayetano Rosell y Juan A. Hartzenbusch'3.

Estreno: Teatro del Circo de Madrid, en febrero de 1863.

\footnotetext{
González, 1861.
} 


\section{Aspectos formales}

1. Título: se mantiene, salvo el artículo.

2. Número y nombre de los personajes: se mantienen todos a excepción del de Mme Godefroy. Se cambian la mayoría de los nombres: André de la Rivonnière es Luis de la Rivonnière; De Tournas, Garán; De Ligneray, Ligneneraye; De Prailles, Valmont; De Naton, Eduardo; Albertine de la Borde, Carlota; Mme de Chavry, la marquesa de Savary; Victorine, Enriqueta. Hélène se traduce: Elena.

3. Acción: se mantiene en París, Dieppe y Fontainebleau, en la misma época.

4. Número de actos: conserva los cinco del francés.

5. En prosa.

6. Acotaciones escénicas: traduce las del original.

7. Estructura dramática:

Del primer acto de la obra francesa, se conservan sólamente parte de los diálogos de la escena 12 y 13 entre el conde y su hijo. El contenido del resto del acto español es creación de los adaptadores. El segundo acto sigue más de cerca al francés: padre e hijo se dirigen a Dieppe a concertar la boda del primero, que termina renunciando en favor de su hijo, al ver el amor surgido entre los jóvenes.

El tercer acto sigue la intriga general del texto original: el padre que vive con el joven matrimonio se dedica a introducir a su nuera en la vida de sociedad y a colmarla de atenciones, creando una situación embarazosa a su hijo. De Tournas (Garán) se encarga de comunicar las murmuraciones del «mundo» que han convertido al padre en rival del hijo. La versión española mantiene esta trama, excluyendo al personaje de Mme Godefroy, la amiga de la familia enamorada del padre y con la que todos quieren que se case, que tiene un papel importante en la obra francesa. Se cortan los parlamentos más largos, reduciendo considerablemente la duración del acto.

El acto cuarto se aparta bastante del texto francés. El personaje de Albertine de la Borde se convierte en Carlota, mujer de dudosa vida, que se emplea de gobernanta en la casa. La relación del conde con Albertine se trueca en la del conde con la gobernanta, con un talante 
completamente diferente. En el texto español el conde quiere casarse con ella; situación nueva.

Del acto quinto se conserva el episodio del duelo del padre con $\mathbf{M}$. de Valmont (de Trélan), el marido de la dama de negro, antigua amante del hijo, como motor de la reconciliación de padre e hijo. El resto es de un contenido y un tono completamente distinto.

Esta versión no sigue la estructura dramática del texto francés; la división de las escenas es distinta, conservando, como hemos dicho, parte de la trama argumental.

\section{Contenido temático}

La versión española confiere un tono muy distinto al problema planteado por Dumas hijo: si éste pretende poner de manifiesto el cansancio de una juventud educada sin más ideales que los del placer y el dispendio y a lo que ello puede conducir, en la obra española se presenta simplemente a un padre calavera creando problemas a un hijo sensato.

Los roles de los personajes han sido modificados sustancialmente: De Ligneray y De Naton que son portadores de ese mensaje de hastio y que reflexionan a la manera Dumas (hijo), se convierten en unos comparsas alrededor de Carlota. El personaje de Carlota no se corresponde con el de Valentine, uno de los mejores de los personajes femeninos creados por el autor francés, maestro en la pintura de los diversos matices de este tipo de mujeres. Valentine, «la courtisane économe» como ella dice, es el tipo de mujer que sabe con su habilidad crearse un puesto en la sociedad superando sus orígenes, un tipo, al decir de los cronistas, bastante frecuente en la época. Carlota es simplemente una mujer de mala vida que pretende engatusar a un viejo. Los adaptadores no supieron ver el matiz que hace al personaje diferente.

\section{Calidad literaria}

La versión española resulta vulgar y tediosa.

L'Ami des femmes (Gymnase Dramatique, 5 de marzo de 1864)

El personaje que da título a la obra, es quizás el más característico de producción del autor. Un hombre dedicado a estudiar a las mujeres, de las que dice conocerlo todo. Además, su tarea consiste en "salvarlas» para que 
no cometan los «deslices» a los que su condición las aboca irremediablemente. Tal personaje sólo podía salir de la pluma de Dumas hijo, porque en realidad este «amigo» es él mismo.

Primera versión: EL AMIGO DE LAS MUJERES

Autor: Jaime Graells Ortega de la Rocha ${ }^{14}$.

Estreno: Teatro Principal el 18 de septiembre de 1898.

I. Aspectos formales

1. Título: se ha conservado traduciéndolo.

2. Número y nombre de los personajes: se han mantenido tanto el número como el nombre de los mismos.

3. Acción: se mantiene en París, «época actual».

4. Número de actos: se mantienen los cinco del original.

5. En prosa.

6. Acotaciones escénicas traducidas, a excepción del añadido de «Un estereóscopo» (es de noche) en el acto II.

7. Estructura dramática:

El primer acto presenta las siguientes modificaciones: la escena 1 a $^{\text {a }}$ de la versión incluye un resumen de las seis primeras escenas de la obra francesa, de las que suprime totalmente las escenas 2 y 3 . De la escena 5 se han suprimido sobre todo los largos parlamentos de De Ryons en el que explica por primera vez su dedicación al estudio de las mujeres, párrafos que no resultan demasiado halagadores para la condición femenina. La escena 2 de la versión corresponde a la

I4 J. Graells Ortega de la Rocha, El amigo de las mujeres, Madrid, Tipografia Sucesor de F. Sánchez, 1899. 
'escena 7 del francés, aunque se suprimen todos los diálogos del género del que mostraremos, muy frecuentes en toda la obra:

\author{
M. LEVERDET \\ «Et l'état de son coeur? \\ DE RYONS \\ «Elle a aimé» \\ M. LEVERDET \\ "Qui? son mari ou un autre?»
}

La escena 3 española, traducción de la 8 del texto francés es la última del primer acto español. Quedan suprimidos pues, la 9, 10 y 11, omitiendo asi la presentación de la relación entre Mme Leverdet y Des Targettes (un «ménage à trois» muy prolongado que se mantiene por la rutina y la amistad del marido y el amante, que forma ya parte de la familia).

En el acto segundo se producen de nuevo cortes en la exposición de las teorías de De Ryons. Algunos cambios corresponden a la adecuación a la diferencia de época (han pasado más de 30 años desde el estreno de la obra de Dumas hijo). La escena 3. incluye resumidas la $4 .^{a}$ y la $5 .^{a}$ del francés, con lo que este acto tiene nuevamente solo tres escenas.

El tercer acto reduce las cinco primeras escenas del original a tres, correspondiendo la 4 de la versión a la 6 del original, y la 5 a la 7 . Se suprime la escena 8 , correspondiendo la 6 a la 9 y la 7 a la 10 . La escena 8 de la versión traduce la 11 y la 12 de la obra francesa, suprimiendo la 13 de ésta.

Del acto cuarto se suprime casi completamente la escena cuarta. El resto de las escenas se traducen resumiendo los parlamentos más largos. Una de las frases que añade el traductor, en la escena 5 difícilmente podía pasar por una afirmación del autor:

DE RYONS

"Una lágrima, ¡cáspita! ¿Valdrán las mujeres más que nosotros?»

El acto quinto sufre sólo modificaciones de detalle, como unir las escenas 4. y 5. en una sola u omitir la alusión al posible matrimonio de De Ryons.

\title{
II. Contenido temático y calidad literaria
}

Se trata de una malísima traducción que mantiene las intrigas de la obra francesa, pero que mutila el propósito fundamental del autor al suprimir 
las abundantes disertaciones del protagonista sobre la condición femenina. Este «amigo de las mujeres» pierde el contenido trascendental que tenía su homónimo francés.

Segunda versión: $E L A M I G O D E L A S M U J E R E S^{15}$

Autores: Enrique F. Gutiérrez Roig y Luis de los Ríos.

Estreno: Teatro Lara de Madrid, 11 de septiembre de 1921.

I. Aspectos formales

1. Titulo: se ha conservado, traduciéndolo.

2. Número y nombre de los personajes: se mantiene el número, cambiando los nombres de la protagonista femenina y su marido que pasan de De Simerose a ser De Varnel. Des Targettes se convierte en Octavio de Nizal.

3. Acción: se mantiene el lugar. La época no coincide con la del original por el tiempo transcurrido entre éste y la versión.

4. Número de actos: se reducen a tres.

5. En prosa.

6. Acotaciones escénicas: más detalladas.

7. Estructura dramática:

El primer acto es la traducción casi exacta del mismo acto francés.

is E. F. GutiérRez-Roig y L. DE Los Ríos, El amigo de las mujeres, Madrid, Imprenta Rafael Caro Raggio, 1921. Existe otra versión idéntica de contenido, aunque no figuran exactamente los mismos traductores: E. F. GutiérRez RoIG y L. Gabaló́n, El amigo de las mujeres, col. «La novela teatral» $n .{ }^{\circ} 339$, Madrid, 1923. La única diferencia es que no existe división en escenas, sino por las entradas de los personajes. 
Los cambios se reducen a algunas supresiones y a la distribución de las escenas; así la escena 1 española agrupa las tres primeras del original, la segunda la 4 y la 5 y la 6 la novena y décima de dicho original.

En el acto II se suprimen las escenas 4 y la 5 . Del tercer acto se suprime la primera, enlazando la escena 3 del segundo acto con la 2 del tercero. De este modo, suprimiendo parte de cada escena, queda incluido el tercer acto francés dentro del segundo acto de la versión. Se cambian algunas anécdotas, se suprimen otras.

A partir de los dos últimos actos de la obra francesa, se forma el tercer acto de esta versión, que consta de ocho escenas, tras suprimir algunos diálogos y los parlamentos más largos. Se mantiene el hilo argumental y las anécdotas principales.

\section{Contenido temático y calidad literaria}

La traducción es correcta y conserva el contenido fundamental de la obra francesa.

\section{Les idées de Mme. Aubray}

Versión: LAS IDEAS DE LA SRA. AUBRAY

Autor: Salvador López Guijarro.

Estreno: Teatro de la Comedia de Madrid, 29 de diciembre de 1893.

\section{Aspectos formales}

1. Titulo: se conserva traducido.

2. Número y nombre de los personajes: se mantiene el número, traduciendo los nombres al castellano.

3. Acción: se mantiene el lugar.

4. Se mantienen los cuatro actos del original.

5. En prosa. 
6. Acotaciones escénicas: se detallan minuciosamente.

7. Estructura dramática:

Se sigue la estructura de la obra francesa, reduciendo considerablemente la duración de las escenas, por el procedimiento de reducir los parlamentos de los personajes.

\section{Contenido temático y calidad literaria}

La intriga principal se mantiene. No existen en esta obra anécdotas, ya que se trata de una obra "de ideas» en la que no quiere desviarse al espectador de la tesis que se defiende: la rehabilitación de la madre soltera en nombre de los principios de la caridad cristiana, y el enfrentamiento entre la moral que se predica y la que se pone en práctica.

El traductor, al suprimir los largos parlamentos moralizadores, atenta contra el contenido de la obra, que pierde parte de su sentido. De todas maneras no parece que con ellos hubiera llegado a convencer a sus compatriotas. Muchos años antes de que la obra hubiera sido traducida, comentaba un periodista de La Época a sus lectores, haciéndose eco del éxito de la obra en París:

«En Francia, ó mejor dicho, en Paris se perdona fácilmente un pasado borrascoso; en nuestro pais no, porque el carácter español es tal que la mujer que delinque y no se prostituye, comprende que merece ser castigada y busca en la soledad el perdón de Dios, pero creeria rebajarse implorando la conmiseración de la sociedad $\aleph^{16}$.

En cuanto a la calidad de la versión, tenemos que repetir una vez más lo poco castellanas que resultan la mayoría de las veces estas versiones que así se denominan.

16 J. Nombela, La Época, 13 abril 1867. 
Une visite de noces (Gymnase Dramatique 10 de octubre de 1871)

Versión: UNA VISITA DE BODAS ${ }^{17}$

Autor: no figura en la edición

Sin noticias del estreno

\section{Aspectos formales}

1. Titulo: se ha traducido

2. Número y nombre de los personajes: se mantiene el número. Se cambian los nombres: De Cygneroi es Sandoval; Lebonnard, Conrado; Lydie (Mme de Morancé), Enriqueta; Fernande (Mme de Cygneroi), Luisa.

3. Acción. Se traslada a las cercanías de Madrid. El texto francés sólo indica «à la campagne»

4. Número de actos: uno, como el original.

5. En prosa.

6. Acotaciones escénicas: se traducen exactamente.

La versión traduce palabra a palabra la obra francesa, sin omitir detalle alguno. Los únicos cambios se producen en las localizaciones geográficas «Lyon ou Havre» se convierten en El Escorial y Valencia; "Dombasie, dans la Meuse» se traduce por Burgos. D. Alphonse, un caballero español que se cita, se "traduce» al francés, conservando el mismo rasgo fonético:

17 Encontré la traducción en la Biblioteca del Arsenal de París, sin referencias de autor, de editor ni de fecha. Sólo consta una dedicatoria en la 1." página: A D. Leandro (ilegible) de Polo, firmada: el traductor. 
"Un espagnol qui avait les cheveux noirs, les pomettes roses, les joues bleues, les dents blanches, les lèvres rouges, et qui trouvait moyen, comme tous les Espagnols, de mettre un (1) dans tous les mots qu'il disait...Rrr!

...uun francés de cabello rubio, sonrosado, de hermosa dentadura y que como todos los franceses ponía su poquito de «r" en cuanto hablaba. ¡Rrr!

La princesse Georges (Gymnase Dramatique 2 de diciembre 1871)

A pesar de que sabemos que se representó a partir de 1885 en castellano por la compañía de María Tubau, no hemos podido localizar la versión castellana de la obra. No hemos encontrado más que un extracto de la misma, de 16 páginas, en la que se narra el argumento y que no merece más comentarios $^{18}$.

M. Alphonse (Gymnase Dramatique 26 de noviembre 1873)

De nuevo el problema de las madres solteras. El apelativo de $\mathrm{M}$. Alphonse, el seductor y padre desnaturalizado, pasó al lenguaje común de la época.

Versión: LA VIUDA DE LÓPEZ ${ }^{19}$

Autor: Luis Mariano de Larra

Estreno: Teatro de la Princesa de Madrid, 12 de marzo de 1886.

18 F. Garcia Vivanco, La princesa Giorgio, Madrid, Imprenta de García y Caravera, 1880.

19 L. M. De LARra, La viuda de López, Madrid, L. Fiscowich, ed. 1886. 


\section{Aspectos formales}

1. Titulo: se ha cambiado.

2. Número y nombre de los personajes: se mantiene el número, modificando los nombres: el comandante Montaiglin es el brigadier Carlos Salazar; Octave, Ricardo Ruiz; Dieudonné, Monleón; Rémy, un criado; Raymonde, Julia; Mme Guichard, la Vda. de López; Adrienne, Clara. Se modifican las edades de los mismos: la viuda tiene ocho o diez años más que Ricardo, en lugar de dos o tres como consta en francés. Salazar tiene dieciocho más que su esposa en vez de quince y la niña tiene siete en vez de once.

3. Acción: se traslada a España, a «una casa de campo en Carabanchel».

4. Número de actos: se mantienen los tres actos.

5. En prosa.

6. Acotaciones escénicas: se traducen las del original.

7. Estructura dramática:

En el acto 1 se presenta a Ricardo aún más desvergonzado que $\mathbf{M}$. Alphonse, añadiendo algunos parlamentos, que se adecuan perfectamente al personaje creado por Dumas (hijo) y que inciden sobre el carácter de $\mathbf{M}$. Alphonse.

El acto II, añade algunas frases que dan un carácter cristiano a la conducta de Salazar, ausente de la intención del autor, al presentar un personaje justo y bueno pero sin esas connotaciones.

$\mathrm{El}$ acto tercero de la versión añade una escena, al desdoblar en dos la escena $3 .^{a}$ del francés.

\section{Contenido temático y calidad literaria}

Salvo los detalles mencionados, la traducción sigue el texto con fidelidad, en un correcto castellano, lo cual no es demasiado frecuente en este tipo de versiones. El detalle de hacer más joven a la hija de $\mathbf{M}$. Alphonse, hace sin embargo inverosímil al personaje, ya que no resultan creíbles sus reacciones. Entre la edad de la versión y la de la obra original existe demasiada dife- 
rencia, sólo explicable por la edad real de la pequeña actriz disponible, ya que de no ser así no entendemos la razón del cambio. Como señala un crítico del estreno:

"Así que al oír en boca de aquella rapazuela las frases que debía decir casi una adolescente, el efecto para mi al menos resultaba contrario, no puede ser la cómplice de su madre» ${ }^{20}$.

Denise (Théâtre Français, 19 de enero de 1885)

Aborda de nuevo Dumas hijo en esta obra el problema de la madre soltera, consiguiendo un gran éxito en París. En nuestro país se conoce muy pronto la versión castellana.

Versión: DIONISIA ${ }^{21}$

Autor: Manuel Tubino y Calderón.

Estreno: Teatro de la Comedia de Madrid, 31 de diciembre de 1885.

\section{Aspectos formales}

1. Titulo: se traduce.

2. Número y nombre de los personajes: se mantiene el número y los apellidos. Se traducen los nombres.

3. Acción: se mantiene en Francia.

4. Número de actos: se conservan los 4 del original.

5. En prosa.

${ }^{20}$ Luis Alfonso, La Epoca, 13 de marzo de 1886.

2 M. Tubino y Calderón, Dionisia, Madrid, Imprenta de José Rodriguez, 1885. 


\section{Acotaciones escénicas: algo más detalladas.}

7. Estructura dramática:

Se conserva exacta la composicion de la obra, que se traduce al pie de la letra, o como dice un crítico de la época:

«En vez de adoptar tan prudente determinación ("dejar a Denise en París"), el encargado de buscar domicilio en Madrid a la doncellita andante de Dumas, tomó el peor camino, cual fue el de traducir al pie de la letra, y más que a la letra, al pien"2.

\section{Contenido temático y calidad literaria}

Obvio es decir que no se altera el contenido, aunque la pésima calidad de la traducción deteriora la pieza francesa.

\section{CONCLUSIONES}

Para concluir, resumiremos algunas reflexiones a las que nos ha llevado el estudio de este teatro. Algunas de ellas han sido esbozadas anteriormente ${ }^{23}$.

Es evidente que una buena parte de la producción teatral de A. Dumas hijo fue conocida en nuestro país, aunque no se conocieran algunas de sus obras más polémicas.

Como señalábamos a propósito de La dame aux camélias, a diferencia de lo que sucede con otros autores franceses contemporáneos, se suele, en la mayoría de las obras, mantener la acción fuera de nuestro país, no se «traspasa» a España. Las razones son siempre las mismas y ya las señalamos.

El interés por este teatro se centra sobre todo (a excepción de Denise,

${ }^{22}$ La Epoca, 2 de enero de 1886.

${ }^{23}$ R. CAlvet, «La imagen de Francia a través del teatro de A. Dumas (hijo)», en Fco. Lafarga (ed.), La imagen de Francia en las letras hispánicas, Barcelona, PPU, 1989. 
la penúltima) en la primera parte de la producción del autor. Dentro de estas obras, las tres primeras que hemos tratado, (las dos primeras versiones de Demi-monde, Le fils naturel y Un père prodigue), se conocen en España con bastante rapidez. El resto de la producción llega a nuestro país con muchos años de retraso.

Existe un "hueco» de casi veinte años, entre la década de los sesenta y la de los ochenta, en la que disminuye totalmente el interés por la producción de este autor, que sin embargo sigue estrenando en París. ¿Habria que buscar las razones en acontecimientos sociales y políticos, en la evolución del teatro autóctono, o en el cansancio de público y traductores?

El retraso en el conocimiento conlleva necesariamente una distorsión en el mensaje, al producirse un gran desfase temporal. Esta distorsión se produce aún más en un teatro concebido para la difusión de unos mensajes muy determinados, con los que se pretende influir en una sociedad muy especifica.

La mala calidad de la mayoría de las traducciónes, así como las distorsiones a las que a veces eran sometidos los textos franceses, no ayudan precisamente a un conocimiento fidedigno del autor.

Estas son sólo algunas de las razones que nos han hecho mantener la hipótesis de que este teatro fue mal conocido en nuestro país y este desconocimiento influyó en el mantenimiento de una serie de tópicos con respecto a la literatura y a la sociedad vecinas. 